\title{
Alternatives for OSAHS treatment: selection of patients for upper airway surgery and oral appliances
}

\author{
A. Boudewyns*, M. Marklund ${ }^{\#}$ and W. Hochban
}

\begin{abstract}
Although continuous positive airway pressure (CPAP) is considered to represent the standard treatment for patients with moderate-to-severe obstructive sleep apnoea/hypopnoea syndrome (OSAHS), poor treatment compliance and/or refusal is an issue in $\sim 20-30 \%$ of these patients.
\end{abstract}

As an alternative to life-long CPAP treatment, conservative procedures exist with dental appliances for mandibular advancement, as well as curative surgical techniques.

Surgical treatment of OSAHS can be divided into the following two main groups: 1) upper airway surgery by soft tissue resection (uvulopalatopharyngoplasty, etc.), and 2) skeletal procedures, such as maxillo-mandibular advancement. Proper selection of patients for the different treatment modalities is the key for full treatment success.

Patient-related factors, such as the site of upper airway collapse, craniofacial characteristics, dental health, obesity, age, profession and positional dependence, as well as treatment-related factors, should be evaluated before a final proposal for these treatment alternatives is formulated.

\section{KEYWORDS: Apnoea, oral appliances, snoring, upper airway surgery}

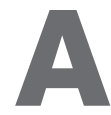
pplication of continuous positive airway pressure (CPAP) is presently the standard treatment for patients suffering from the obstructive sleep apnoea/hypopnoea syndrome (OSAHS). The American Academy of Sleep Medicine formulated the indications for alternative treatment options as follows. 1) Surgical treatment is indicated to treat those patients who have an underlying specific surgically correctable abnormality that is causing the sleep apnoea. Surgery may be indicated to treat OSAHS in patients for whom other noninvasive treatments have been either unsuccessful or rejected, who desire surgery and who are medically stable enough to undergo the procedure [1]. 2) Oral appliances are indicated for use in patients with mild-to-moderate OSAHS who prefer them to, who do not respond to, are not appropriate candidates for, or who fail treatment attempts with CPAP therapy [2]. Apart from CPAP refusal or noncompliance, additional patient-related factors must be taken into account when selecting patients for one or another alternative treatment option. The present article aims to provide a comprehensive overview of the current knowledge about parameters that might help in the selection of both patients and treatment options.

\section{ALTERNATIVE TREATMENT OPTIONS The upper airway collapse}

A partial or complete collapse of the upper airway (UA) during sleep is the hallmark of the OSAHS. This collapse occurs at a discrete locus (of $\sim 1 \mathrm{~cm}$ ) that can be located anywhere between the choanae and the epiglottis. Only a minority $(1-5 \%)$ of OSAHS patients have a specific spaceoccupying abnormality in the UA for which surgical removal is corrective. In the majority of OSAHS patients, there is a diffuse pattern of UA narrowing during sleep involving the soft palate, lateral pharyngeal walls and tongue base. This is often referred to as "disproportionate anatomy", i.e. unfavourable anatomical features of the surrounding soft tissues and underlying facial skeleton, predisposing to OSAHS.

\section{Upper airway surgery for OSAHS}

Surgical treatment of OSAHS aims to correct anatomical abnormalities in the UA contributing to its collapse during sleep. At present, two relevant treatment strategies exist.

The first approach is to perform soft tissue surgery in an attempt to remove redundant UA tissue or to reduce the volume of UA structures that are implicated in the UA collapse. This

\section{AFFILIATIONS}

*Dept of Otorhinolaryngology, Head and Neck Surgery, University Hospital Antwerp, Belgium.

\#Dept of Orthodontics, Umeå

University, Umeå, Sweden, and

"Craniomaxillofacial Surgery,

Radolfzell/Bodensee, Germany.

CORRESPONDENCE

A. Boudewyns

Dept of Otorhinolaryngology

Head and Neck Surgery

University Hospital Antwerp

Wilrijkstraat 10

2650 Edegem

Belgium

Fax: 3238250536

E-mail: an.boudewyns@uza.be

STATEMENT OF INTEREST

The present article was presented as part of the international symposium "Respiratory somnology: a clinical update", sponsored by GlaxoSmithKline, Belgium. 
approach goes back to the well-established technique of Ikematsu, who, in 1964, inaugurated uvulopalatopharyngoplasty (UPPP) for the treatment of snoring with the intention to resect or surgically correct the specific site of obstruction in the UA. The widespread use of UPPP for OSAHS led to variable results, mainly because UPPP addresses only the velopharyngeal segment of the UA [3]. Consequently, additional surgical techniques have been developed to focus on different sites of obstruction mainly located at the tongue base and lateral pharyngeal walls.

Nevertheless, UPPP is still the most frequently performed surgical procedure for OSAHS. The complications that may result from UPPP are usually relatively minor. A $1.5 \%$ incidence of serious life-threatening complications and a mortality rate of $0.2 \%$ was found in a prospective study by KEZIRIAN et al. [4]. The success of UPPP in unselected OSHAS patients is poor, as only $40.7 \%$ of these subjects could be classified as responders [3]. It has been suggested that surgeons who have failed to pre-operatively identify the site of obstruction probably overuse UPPP and that this might explain the unfavourable results associated with this procedure [5]. Failure of UPPP to correct OSAHS is usually attributed to a lack of modification at secondary sites of obstruction located more caudally in the UA. The present authors performed UA pressure measurements during sleep before and after UPPP, and confirmed the persistence of UA obstruction at the level of the tongue base and hypopharynx [6]. Other factors contributing to UPPP failure are persistent retropalatal collapse due to an increased thickness of the soft palate after surgery, post-operative weight gain and smoking. The idea of a persistent OSAHS due to retrolingual collapse after UPPP has prompted the development of surgical modalities addressing the hypopharyngeal airway.

A detailed description of various surgical techniques and their respective results may be found elsewhere [7, 8]. A schematic overview of the most common surgical procedures for
OSAHS and their respective site of action is presented in table 1.

The second approach considers the skeletal dimensions of the face (viscerocranium) with the position of the jaws, which have a major influence on the shape of the UA and its diameter. Pharyngeal narrowing may be caused by skeletal anatomical patterns of the face, e.g. small and retrognathic mandible. The viscerocranium, mainly the position and development of the jaws, is the skeletal basis for UA size and patency. All muscles of the UA have their origin at bony protuberances of the maxilla or mandible. These are all the velopharyngeal muscles, the tongue muscles and the suprahyoid muscles. Numerous inherited or acquired clinical syndromes with craniofacial changes are significantly associated with OSAHS and demonstrate the importance of jaw position and size. The most famous example is the Pierre-Robin sequence: a mandibular deficiency leading to retrusion of the tongue (glossoptosis) with obstruction of the UA, which is enhanced by the open palatal cleft.

Even minor changes of form and position of the mandible and/ or maxilla in relation to the facial skeleton may have functional consequences on UA collapsibility. The occurrence of OSAHS is increased if mandibulary or maxillary retrognathia is associated with certain craniofacial and morphological characteristics, such as vertical and dolichofacial type. A dolichofacial type means a steeply raising mandibular base, which promotes a dorsal and caudal displacement of the chin and the adjacent tongue base and suprahyoid musculature. Among patients with relevant OSAHS, $\sim 40 \%$ have these characteristic craniofacial criteria predisposing to UA collapse [9].

Yet another surgical approach is to bypass UA collapse by tracheotomy, which is the last option and nowadays should be avoidable.

All these different procedures yield some success in some patients; the major problem is careful selection of proper candidates who respond at high warranty to the proposed

TABLE 1 Surgical procedures for obstructive sleep apnoea/hypopnoea syndrome and their respective mechanisms and site(s) of action

\begin{tabular}{|c|c|c|}
\hline Mechanism of action & Upper airway site of action & Procedure \\
\hline \multirow[t]{3}{*}{ Soft tissue removal } & Retropalatal & Uvulopalatopharyngoplasty \\
\hline & & Laser assisted uvulopalatoplasty \\
\hline & & Tonsillectomy \\
\hline \multirow[t]{4}{*}{ Tissue volume reduction } & Retropalatal & RTVR of the soft palate and/or tonsils \\
\hline & Retrolingual & Laser midline glossectomy/lingualplasty \\
\hline & & RTVR of the tongue base \\
\hline & Retrolingual/retropalatal & Uvulopalatopharyngoglossoplasty \\
\hline \multirow{5}{*}{$\begin{array}{l}\text { Skeletal modification resulting in soft tissue } \\
\text { repositioning }\end{array}$} & Retropalatal & Transpalatal advancement pharyngoplasty \\
\hline & Retrolingual & Mandibular advancement \\
\hline & & Genioglossal advancement \\
\hline & & Hyoid myotomy and suspension (type I and II) \\
\hline & Retropalatal and retrolingual & Maxillomandibular advancement \\
\hline Bypass upper airway & & Tracheotomy \\
\hline
\end{tabular}

RTVR: radiofrequency tissue volume reduction. 
surgical procedure. Therefore, the surgeon must understand the pathophysiology of UA mechanics [10], and proceed through a careful selection process.

\section{Oral appliances for OSAHS}

In the present section about oral appliances, the focus will be on mandibular repositioning appliances, as they represent the most effective and wide-spread type of oral device [11, 12]. Mandibular repositioning appliances (MRAs) hold the lower jaw forward and downward in order to reposition the tongue and soft palate in the same direction with the aim to widen the whole UA during sleep (fig. 1) [2, 11, 13, 14].

\section{Mechanism of the device}

It has been shown that MRAs enlarge the UAs at several points, both at the soft palate and at the base of the tongue (fig. 1) [15]. There is predominantly a lateral enlargement of the UA, but anterior-posterior expansion has also been observed [16, 17]. In this way, the tongue gains more space and moves forward [18]. The pharyngeal collapsibility and critical pressure diminish with the device in place $[15,19,20]$. Even so, more precise knowledge is needed about the mechanism of the device in order to increase the understanding of the variability in treatment response that has been observed between patients.

\section{Effects of mandibular repositioning appliances}

There are clear short-term reductions in sleep apnoeas, minimum oxygen desaturation and subjective sleepiness from MRAs compared with control devices or a placebo tablet in patients with OSAHS [13, 21, 22]. On average, snoring is halved in frequency and loudness [23]. In the longer term, snoring and sleep apnoea increase slightly according to a few case series or in comparison with surgery [24-27].

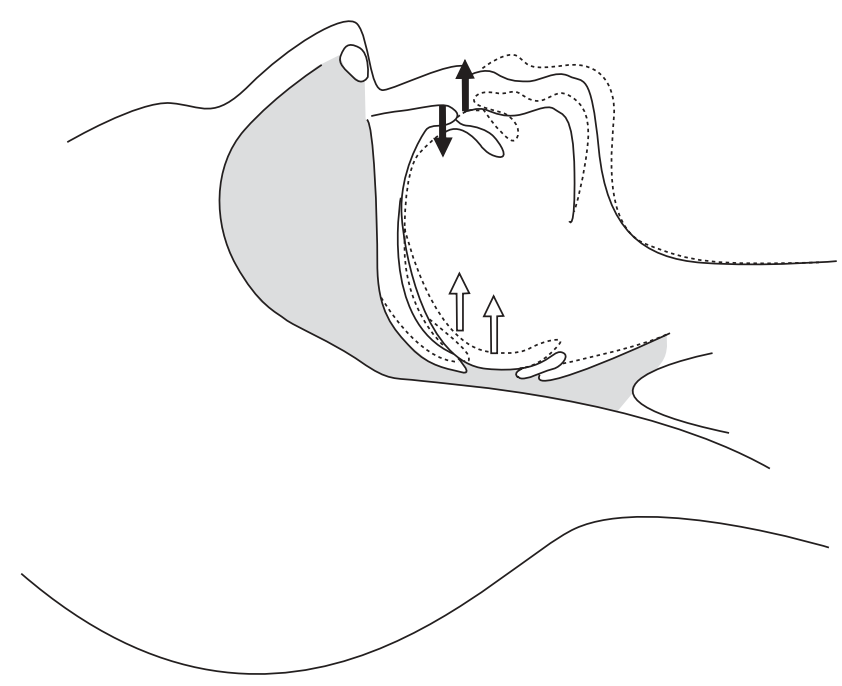

FIGURE 1. Illustration of the widening in the upper airway and possible sideeffects on the teeth from the mandibular repositioning appliance. The empty arrows in the pharynx show the forward movement of the tongue and soft palate. The filled arrows on the teeth indicate the tooth movements with the upper incisors going backwards and the lower incisors shifting their position forwards.
Future larger-scale studies including treatment effects on symptoms of sleep apnoea are required. It is also important to assess whether the effects on sleep apnoeas and symptoms are stable from night to night, as well as in the longer term.

\section{Oral side-effects}

The short-term side-effects of MRAs, such as excessive salivation and tenderness of teeth or jaws, usually disappear with time $[13,15]$. In the longer term, bite changes become more common. The cause of bite changes emerges from the forward and vertical displacement of the mandible, which is performed to prevent UA collapse during sleep. The forces that are produced reduce the normal distance between the upper front teeth and lower front teeth and the bite opens up in its posterior parts (fig. 1) [15, 28-30]. A change in the dental occlusion of $>1 \mathrm{~mm}$ occurs in about one-third of the patients after 5 yrs [30].

\section{SELECTION OF PATIENTS FOR ALTERNATIVE TREATMENTS}

Routine clinical investigation in OSAHS patients should start with careful investigation of the whole UA by a trained specialist prior to any kind of treatment [31]. Clinical investigation is important not only with respect to possible surgical corrections, but also to exclude pathological conditions prior to conservative treatment with CPAP or MRA. Improved nasal ventilation, for instance, might help to reduce CPAP pressure. The clinical investigation should also include the status of the teeth, their position and the maxillomandibular relationship as overjet and overbite, which gives a first hint to craniofacial disorders and whether the patient is suitable for an oral appliance.

\section{Selection of patients for upper airway surgery}

An overview of the various factors to be considered in selecting patients for UA surgery is listed in table 2 and will be discussed in the following sections.

Clinical findings and site(s) of upper airway obstruction

The importance of pre-operatively determining the site of UA obstruction in surgical candidates was first emphasised by SHER et al. [3]. FRIEDMAN et al. [32] proposed a staging system based upon tongue position (modified Mallampati score), tonsil size and body mass index (BMI) to predict success for UA surgery (table 3 ).

$\begin{aligned} & \text { TABLE } 2 \text { Factors contributing to the selection procedure of } \\ & \text { obstructive sleep apnoea/hypopnoea syndrome } \\ & \text { (OSAHS) patients for upper airway (UA) surgery }\end{aligned}$
Clinical findings/technical examinations and site(s) of UA
obstruction
OSAHS severity
Obesity
Comorbidities
Anaesthetic risk
Willingness of the patient to comply with the proposed treatment
schedule
Surgical experience
Patient's profession




\begin{tabular}{|c|c|c|c|}
\hline Stage & Tongue position ${ }^{\#}$ & Tonsil size $\mathrm{e}^{\#}$ & BMI $\mathbf{k g} \cdot \mathrm{m}^{-2}$ \\
\hline I & 1 or 2 & 3,4 & $<40$ \\
\hline \multirow[t]{2}{*}{ II } & 1 or 2 & $0,1,2$ & $<40$ \\
\hline & 3 or 4 & 3,4 & $<40$ \\
\hline \multirow[t]{2}{*}{ III } & 3 & $0,1,2$ & $<40$ \\
\hline & 4 & $0,1,2$ & $<40$ \\
\hline IV & $1,2,3,4$ & $0,1,2,3,4$ & $>40$ \\
\hline
\end{tabular}

Data modified from [32]. BMI: body mass index. ${ }^{\#}$ : increasing values indicate higher tongue positions and larger tonsil sizes, respectively.

A retrospective analysis of 134 patients undergoing UPPP as an isolated procedure indicated a success rate of $80.6 \%$ for stage I patients, $37.9 \%$ success for stage II patients and $8.1 \%$ for stage III patients. In another study regarding the efficacy of the Pillar implant technique, FRIEDMAN et al. [33] found a correlation between this scoring system and clinical outcomes. The value of this staging system was later questioned by DEN HERDER et al. [34], as these authors found that patients with a modified Mallampati score of 3 or 4 (indicating a large tongue) often had retropalatal obstruction during sleep endoscopy. Presently, studies are taking place to investigate whether combining of data from sleep endoscopy together with the Friedman score would result in better treatment advice, as compared with the use of data solely from one or the other.

\section{Technical examinations and site of upper airway collapse}

In an attempt to understand the functioning and behaviour of the UA, various techniques permitting UA characterisation have been developed. A detailed description of these methods, including static and dynamic techniques, and evaluations during wakefulness or sleep is beyond the scope of the present article and can be found elsewhere [10,35-37]. Herein, the focus will be on the relevant techniques that are routinely used in clinical practice to improve the surgical outcome of patients, with an emphasis on cephalometric analysis and sleep endoscopy. The concept of evaluating UA collapsibility by measuring the critical closing pressure (Pcrit) will also be addressed.

\section{Sleep endoscopy}

Sleep endoscopy refers to the fibre-endoscopic examination of the UA during drug-induced sleep [38]. Sleep can be induced by intravenous administration of either midazolam or propofol. Some countries developed guidelines for i.v. administration of midazolam by a doctor who is not an anaesthesiologist (table 4) [39].

Strict adherence to these guidelines is mandatory in order to prevent complications. The current authors recommend that sleep endoscopy should be performed in the operating room, in collaboration with the anaesthesiologist, with continuous pulse oximetry and the potential to intubate and ventilate on stand-by.

Drug-induced sleep is not a natural form of sleep, but endoscopic UA examination during natural sleep is poorly tolerated by most patients and is difficult to perform in routine clinical practice. QuINN et al. [40] compared endoscopic findings during natural sleep with those obtained during drug-induced sleep and found a basic agreement between both methods in terms of site(s) of UA obstruction. A major advantage of sleep endoscopy is that it permits a dynamic and visual evaluation of the UA at the level of the nasopharynx, oropharynx and tongue base, and it also provides information about the involvement of lateral wall collapse. Based upon these findings, a site-specific treatment scheme can be proposed [38, 41]. HESSEL and DE VRIES [41] investigated the value of sleep endoscopy in the selection of patients waiting for UPPP. Of the 52 OSAHS patients for whom pre- and post-operative polysomnographic data were available, $32(62 \%)$ had a successful outcome defined as a postoperative apnoea/hypopnoea index $(\mathrm{AHI})<20$ events $\cdot \mathrm{h}^{-1}$. The authors therefore concluded that the success rate of UPPP increases as compared with historical controls after a diagnostic work-up including polysomnography and sleep endoscopy. Another study from the same investigators illustrates the value of sleep endoscopy in the selection of patients for hyoid suspension. In the study by DEN HERDER et al. [42], the overall success rate of hyoid suspension was $52 \%$ after selection of patients based upon the presence of tongue base obstruction documented by clinical examination and sleep endoscopy. These results are much better than those published by BOWDEN et al. [43] in a group of more obese OSAHS subjects. In this population, the success rate of hyoid suspension as a single treatment option was only $17 \%$. Had sleep endoscopy been performed in these patients, it is likely that the results would have suggested that these patients were unfavourable candidates for hyoid suspension (personal communication, N. De Vries, St.Lucas Andreas Hospital, Dept of Otorhinolaryngology, Head and Neck Surgery, Amsterdam, The Netherlands).

At present, data from the literature suggest that sleep endoscopy results in a modest improvement of success rates for UPPP. However, it seems that the value of this technique lies more in its ability to predict which patients have multiple sites of UA obstruction (especially at the level of the tongue base) and are in need of a surgical intervention at these various levels in order to achieve a successful outcome.

\section{Cephalometric analysis}

A cephalometric analysis refers to a lateral radiographic view of the head and neck in a standard plane and performed under standard conditions [37, 44, 45]. Radiographic cephalometry is a two-dimensional (sagittal and vertical) measurement of a lateral radiographic head film, which is refined for projection and magnification errors by the use of a cephalostat and longfocus-film and short-object-film distances. In addition to the conventional skeletal parameters for the judgement of the viscerocranium, developed a century ago, the assessment of pharyngeal soft tissue dimensions is essential in the diagnosis of OSAHS. It has been shown that cephalometric twodimensional parameters correlate accurately with three-dimensional parameters of computed tomography (e.g. length of the soft palate) [46]. The assessment of defined anatomical and constructed skeletal and soft-tissue landmarks allows the measurement of certain angles and distances that characterise craniofacial relation and configuration [37, 45]. 


\begin{tabular}{|c|c|}
\hline $\begin{array}{ll}\text { TABLE } 4 & \text { Inclusion and } e \\
\text { endoscopy afte }\end{array}$ & $\begin{array}{l}\text { sion criteria for sleep } \\
\text { ministration of midazolam }\end{array}$ \\
\hline $\begin{array}{l}\text { Inclusion criteria for sleep } \\
\text { endoscopy }\end{array}$ & $\begin{array}{l}\text { Exclusion criteria for sleep } \\
\text { endoscopy }\end{array}$ \\
\hline $\begin{array}{c}\text { AHI }<40 \text { events } \cdot h^{-1} \text { or } \mathrm{Al} \\
<30 \text { events } \cdot \mathrm{h}^{-1} \\
\text { ASA classification I and II } \\
\text { Invasive intervention or surgery is } \\
\text { considered }\end{array}$ & $\begin{array}{c}\text { AHI }>40 \text { events } \cdot h^{-1} \text { or } \mathrm{Al} \\
>30 \text { events } \cdot h^{-1} \\
\text { ASA classification }>\| \\
\text { Severe obesity } \\
\text { Alcohol abuse } \\
\text { Invasive intervention or surgery } \\
\text { is not considered } \\
\text { Conservative management is } \\
\text { preferable }\end{array}$ \\
\hline
\end{tabular}

Data modified from [39]. AHI: apnoea/hypopnea index; Al: apnoea index; ASA: American Association of Anesthesiology.

Differences between snorers and OSAHS patients in the hyoid position, tongue length and intermaxillary space have been documented [47]. Comparisons of the craniofacial complex between OSAHS subjects and their siblings without OSAHS indicated that a lower-position of the hyoid bone in relation to the mandibular plane is significantly associated with OSAHS after correction for age and BMI [48]. MiLlMAN et al. [49] investigated the value of cephalometric analysis in the selection of patients for UPPP among a group of 46 OSAHS patients. A successful outcome was directly related to the position of the hyoid bone: a distance between the mandibular plane and the hyoid bone $\leqslant 20 \mathrm{~mm}$ was the single most significant predictor of success. The authors suggested that a lower position of the hyoid bone results in a greater potential for collapse of the tongue into the hypopharynx, which might contribute to failure of UPPP as a single procedure in these subjects. In addition, retrognathia (where the angle between the nasion-maxilliary line and the nasion-mandibular line is $\geqslant 3^{\circ}$ ) was found to have a negative impact on treatment outcome.

Cephalometric analysis is of paramount importance in the selection of patients for maxillomandibular advancement surgery. In $\sim 40 \%$ of OSAHS patients (mainly nonobese), typical craniofacial abnormalities can be documented by this technique, the majority having a mandibular and/or maxillary deficiency with dorsocaudal rotation of the mandibulo-maxillary complex and narrowing of the posterior airway space [50]. In these subjects, maxillomandibular advancement (MMA) can be considered as the firstline treatment alternative to CPAP (fig. 2) [9].

Cephalometric evaluation is simple, quick, cheap, noninvasive, easy to perform and reproducible and its merit in the diagnostic approach for OSAHS patients has been proven. Not only is it helpful in selection of patients for UA surgery, but also as a primary diagnostic tool with respect to determination of the causes of OSAHS in an individual patient.
Measurement of upper airway collapsibility: Pcrit

The study of pressure-flow relationships in the UA during sleep allows the definition of two parameters that determine the severity of UA obstruction during sleep: the pharyngeal $P$ crit and the resistance upstream to the site of pharyngeal collapse. Pcrit can be considered as a measure of UA collapsibility and varies along a continuum from health (low collapsibility; $P_{\text {crit }}<$ atmospheric pressure) to disease (high collapsibility; $P_{\text {crit }}>$ atmospheric pressure); specific treatment strategies have been shown to result in a predictable decrease in $P_{\text {crit }}$ [51]. MMA, for example, results in a major decrease of $P$ crit by $\sim 4 \mathrm{cmH}_{2} \mathrm{O}(\sim 0.4 \mathrm{kPa})$ [52]. Standardised protocols have been developed to determine $P$ crit in clinical practice [53, 54]. Measurement of $P$ crit provides a physiological approach to investigate patients with varying degrees of sleep-disordered breathing (SDB) and to investigate the effect of a particular treatment on UA collapsibility [55-58]. Effective treatment of obstructive apnoea and hypopnoea can only be obtained when $P$ crit decreases to close to $-4 \mathrm{cmH}_{2} \mathrm{O}(-0.4 \mathrm{kPa})$, thus converting patients from obstructive sleep apnoea sufferers to snorers.

\section{OSAHS severity}

Most studies on UA surgery indicate a worse outcome in patients with severe OSAHS in terms of apnoea severity [3, 59, 60]. When looking to the pathophysiology of OSAHS and UA collapsibility, this can be easily understood. Patients with more severe OSAHS have a higher UA collapsibility (higher critical closing pressure) during sleep [51]. Specific treatment options are known to lower $P_{\text {crit }}$ by a given amount [52, 57, 58]. Knowledge of $P_{\text {crit }}$ for a given patient prior to treatment, and information about the magnitude of the $P$ crit change that can be obtained by a particular treatment, can be used to select patients for a specific treatment or a combination of treatment strategies [51].

In patients with very high Pcrit values, a procedure with a major effect on UA collapsibility, such as MMA, might be required, or it might be necessary to combine different treatment strategies (for example, weight reduction and surgery or different surgical procedures) to have an additive effect.

Conversely, some studies indicate that OSAHS severity in terms of AHI is not related to outcome. FRIEDMAN et al. [61] found that patients with mild disease based on polysomnographic data are not more likely to have a successful outcome after UPPP as compared with patients with severe disease, and the Friedman scoring system was found to be more reliable to predict surgical success. For example, patients with mild disease based upon AHI $<20$ events $\cdot \mathrm{h}^{-1}$ had only $11.5 \%$ success if they were in stage III (Friedman score), but had $69.2 \%$ success if they were in stage I (Friedman score). HesseL and DE VRIES [62] did not find a statistically significant difference in pre-operative $\mathrm{AHI}$, age or BMI between 32 OSAHS patients classified as successful after UPPP (AHI $\leqslant 20$ events $\cdot h^{-1}$ ) and 23 OSAHS patients considered to be failures. In the present authors' own experience, OSAHS severity is not a restriction for MMA, and success with postoperative reduction of AHI $<10$ events $\cdot h^{-1}$ was true for patients with a pre-operative $\mathrm{AHI}$ with a range of up to 101 events $\cdot h^{-1}$ (personal communication, W. Hochban, Craniomaxillofacial Surgery, Radolfzell/Bodensee, Germany). 

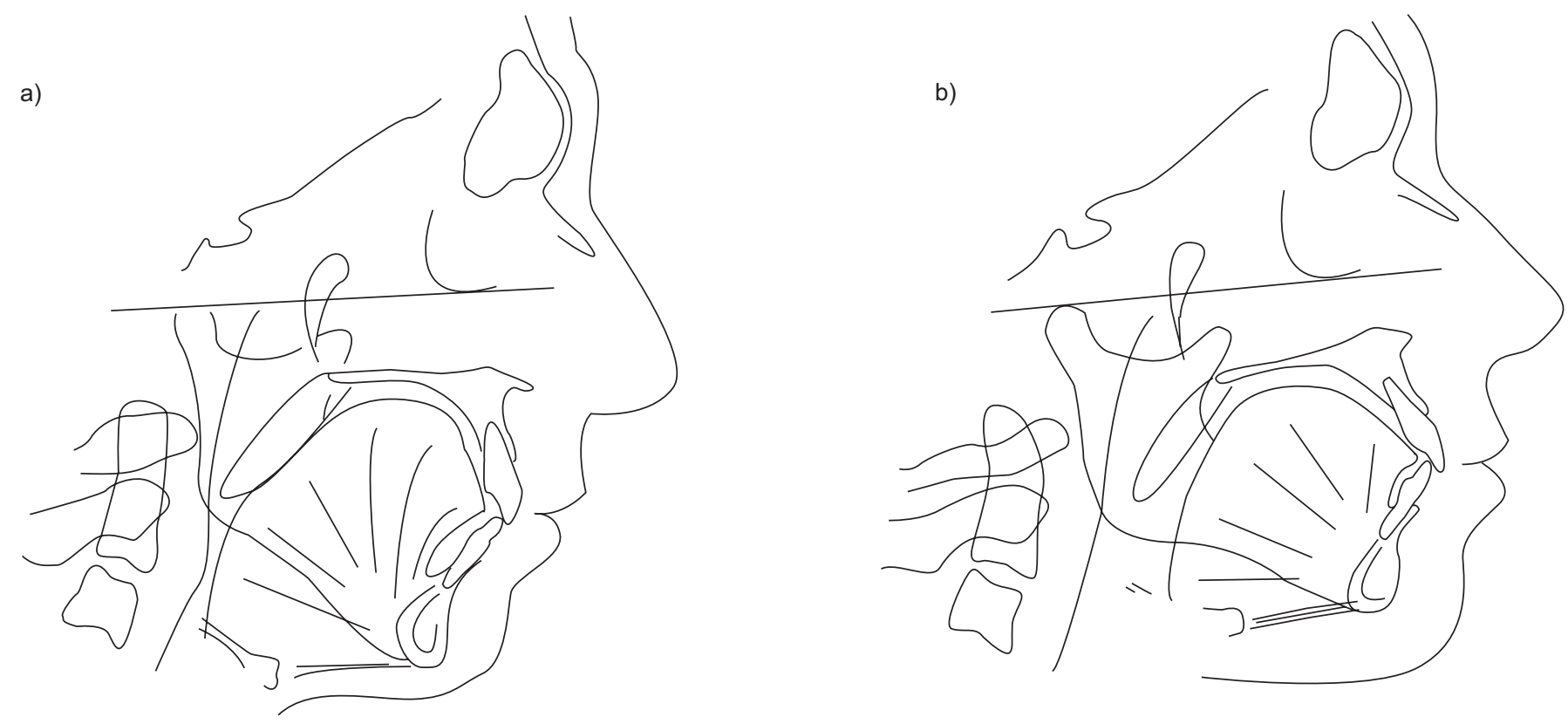

FIGURE 2. Cephalometric presentation of dolichofacial type (a) with consecutive pharyngeal obstruction ( $\sim 40 \%$ of all patients with obstructive sleep apnoea/hypopnoea syndrome) compared with "normal" mesofacial type (b). Retrognathic dolichfacial type (a) is a clear indication for surgical correction by maxillomandibular advancement.

The knowledge about the relationship between OSAHS severity and treatment outcome will probably be challenged in the future, as present knowledge about the definitions of disease severity is continually evolving.

\section{Obesity}

Obesity is the most important risk factor for OSAHS in the middle-aged, adult population and it has been identified as a poor prognostic factor in sleep apnoea surgery [59, 63, 64]. In some studies, deterioration of surgical results over time has been associated with post-operative weight gain [65], whereas others did not find this association [59]. The exact mechanisms behind the relationship between OSAHS and obesity are not yet known, although a reduction in UA collapsibility after weight loss has been demonstrated [58]. Moreover, obese subjects are more likely to have comorbid conditions and difficulties with airway management and ventilation (reductions in functional residual capacity and increased whole-body oxygen demand), placing them in an unfavourable position for procedures under general anaesthesia [66]. Li et al. [67] specifically investigated the results of an UA reconstructive procedure (according to the Stanford protocol) in a group of 21 morbidly obese subjects (BMI $45 \pm 5.4 \mathrm{~kg} \cdot \mathrm{m}^{-2}$ ) with severe OSAHS (AHI $83.0 \pm 30.1$ events $\cdot h^{-1}$ ). All patients completed the two-phased protocol and had an MMA with a significant reduction in post-operative AHI to $10.6 \pm 10.8$ events $\cdot h^{-1}$. Critical analysis of the data presented in the report by LI et al. [67] indicated that other factors might have contributed to these favourable results [68]. Twelve out of the 21 patients had baseline abnormal craniofacial data and there was a significant decrease in BMI from baseline (BMI $45 \pm 5.4 \mathrm{~kg} \cdot \mathrm{m}^{-2}$ ) to the final polysomnography (BMI $43 \pm 4.4 \mathrm{~kg} \cdot \mathrm{m}^{-2} ; \mathrm{p}<0.001$ ).

According to the Marburg protocol for maxillomandibular advancement $[69,70]$, excessive obesity $\left(\mathrm{BMI}>38 \mathrm{~kg} \cdot \mathrm{m}^{-2}\right)$ and the lack of severe cephalometric craniofacial changes is a contraindication for surgical treatment by MMA due to the multifactorial origin and pathophysiology of OSAHS [10, 6971]. Weight reduction can be accompanied by effective conservative treatment until the decision for surgery is reached.

\section{Comorbidities and anaesthetic risk}

OSAHS can be associated with significant cardiovascular and metabolic disturbances [72, 73]. In addition, typical OSAHS features, such as a fat thick neck, large tonsils, redundant pharyngeal mucosa, large tongue base and short thyromental distance, place these patients at risk for intubation difficulties. A consensus paper has been published by the American Association of Anaesthesiologists and guidelines were proposed for safe anaesthetic management of OSAHS patients [74]. As the majority of OSAHS patients have multiple sites of UA obstruction during sleep, there is a tendency among surgeons to combine various surgical procedures during one single operative session or to propose a stepwise surgical protocol, implying repeated anaesthesia. The safety of combining nasal and palatal surgery has been addressed in only a few studies [75, 76]. MMA is effective immediately after surgery, and therefore the anaesthetic risk post-operatively is considerably low [77]. Nevertheless, due to the potential pathophysiological consequences of OSAHS (hypertension, etc.), a conservative treatment prior to surgery over a few months might be helpful to reduce risks and side-effects [71].

\section{Willingness of the patient to comply with the proposed treatment} schedule

Some forms of UA surgery, such as radiofrequency tissue volume reduction (RTVR) of the soft palate, tongue base and turbinates, are performed in more than one treatment session, either isolated or combined. In a review of 322 patients treated with 497 RTVR sessions, the mean number of treatment 
sessions per patient was 1.7 for the tongue base, 1.4 for the soft palate and 1.0 for the turbinates [78]. However, in this study [78], the number of RTVRs is probably rather low because 258 treatments were combined with other forms of UA surgery, such as nasal surgery, oropharyngeal surgery or hyoid suspension. In a study by STUCK et al. [79] of 20 OSAHS subjects, RTVR of the tongue base was performed in a mean of 3.4 treatment sessions performed 4-6 weeks apart. In a study by LI et al. [80] of RTVR of the tongue base, patients had a mean number of 5.5 treatment sessions. FISCHER et al. [81] performed multiple radiofrequency lesions in one single treatment session (soft palate, tongue base and tonsils), but this was found to have limited efficacy as the AHI (mean \pm SD) decreased from $32.6 \pm 17.4$ to $22.0 \pm 15.0$ events $\cdot h^{-1}$.

Other protocols for staged UA surgery have been proposed by the Stanford group, amongst others [41, 64, 82]. A staged approach for UA surgery implies repeated anaesthetic procedures, hospitalisations and absenteeism from the workplace. Moreover, from a theoretical point of view, the results of each surgical step, and thus the validation of the next step, should be justified by a polysomnographic examination as there is often a discrepancy between objective and subjective results. This might be difficult to realise in clinical practice, given the limited capacity of sleep centres in some countries or regions and the increased cost of such an approach.

The need for multiple interventions might be avoided by choosing a surgical treatment that affects the entire UA at once, such as MMA [83]. The Marburg protocol schedules surgical MMA of about $10 \mathrm{~mm}$ as a first-step procedure [70,71]. This primary procedure is successful in $95 \%$ of cases selected according to cephalometric parameters [69, 84, 85]. Even if fewer than $5 \%$ of the cases need additional refinements as second-stage procedures for complete success at that level, patients must be informed and willing to accept and follow this procedure.

\section{Surgical experience}

GUPTA and REITER [86] performed a survey among otolaryngologists involved in the treatment of OSAHS. Out of the 2,000 surveys mailed, 305 (15\%) were returned. Almost all respondents perform tonsillectomy, palatoplasty, septoplasty or turbinate reduction to treat SDB, but only $28 \%$ used any procedure to address the hypopharyngeal airway such as genioglossus advancement or hyoid suspension. Furthermore, only $30 \%$ had experience with innovative technologies to address tongue base collapse, such as RTVR of the tongue base or the repose tongue suspension procedure, and only $3 \%$ performed MMA. Although the response rate in this survey is small, it highlights an important problem in the surgical treatment of OSAHS patients. Collapse of the UA during sleep is often a complex multilevel problem, and failure to perform varied surgical techniques approaching the entire UA may contribute to the limited success of UA surgery in these patients. Thus the surgeon performing "sleep-surgery" should be experienced to offer all the different surgical treatment options, as well as the relevant diagnostic procedures to make the best decision for the patient. However, a good rhinoplastic surgeon is not necessarily a good obstructive sleep apnoea surgeon. The overall fitting and applicable surgical procedure does not exist, which is not surprising due to the complex underlying pathophysiology of UA collapse in OSAHS.

\section{Implications of surgery on the patient's profession}

Articulatory changes can occur after velopharyngeal surgery. Nevertheless, a systematic analysis including nasometry and phonetic analysis after UPPP revealed no significant postoperative changes in nasality, voice and articulation, and a significant change in nasalance occurred only for the high vowel " $\mathrm{I}$ " [87]. This might, however, be of significance for professional voice users and appropriate pre-operative counselling, preferentially by a logopedist, is advocated.

\section{Selection of patients for mandibular repositioning appliances}

Patient selection is essential in order to increase the success rate with MRAs, otherwise CPAP will generally be a better treatment modality, since it more effectively reduces sleep apnoeas and increases oxygenation [13]. On average, about half of patients with mild-to-moderate sleep apnoea experience treatment success with MRAs, defined as a reduction in the AHI to $<5$ or 10 events $\cdot h^{-1}$ [11]. The relief of symptoms is sometimes included in the definition of treatment success, but no exact cut-off point for the symptomatic improvement has been defined so far. In addition, the risk for dental side-effects has to be added in the evaluation of suitable candidates for MRA treatment. An overview of the various factors to be considered in selecting patients for MRA treatment is listed in table 5 and will be discussed in the following sections.

\section{Upper airway/facial morphology}

Successfully treated patients obtain a larger increase in UA size from their MRAs than patients with treatment failure, independent of the degree of mandibular advancement and disease severity [18]. The soft palate moves further forward and the pharynx becomes flatter in good responders compared with nonresponders [18]. The factors determining these effects are unknown. It is most likely that individual characteristics in pharyngeal anatomy are linked to the response in the pharynx and the effects from the device on sleep apnoeas. Various imaging techniques have therefore been used to identify morphological predictors for treatment success, although the findings from such studies are often inconsistent. Most commonly used are different variables defined on cephalograms. Patients with a short uvula of $\leqslant 30 \mathrm{~mm}[88,89]$ have a high chance of receiving treatment success with MRA. It is most likely that a short uvula will obstruct the airway less often, despite an advanced position of the mandible compared with a long uvula. It also seems beneficial for the patients to have a narrow pharynx in the antero-posterior direction [8992], but a wide retropalatal space has also been related to treatment success [93]. A wide pharynx could be the result of a protective mechanism to avoid airway collapse in patients with obstructive sleep apnoea [94, 95]. This could explain why patients with a narrow airway in the antero-posterior dimension would benefit more from an MRA. The position of the jaws may also influence the effects in the pharynx from the mandibular repositioning procedure. Thus, patients with a narrow mandibular plane angle and normal or large mandible have been found to increase their cross-sectional area in the pharynx more compared with patients with steep mandibular 


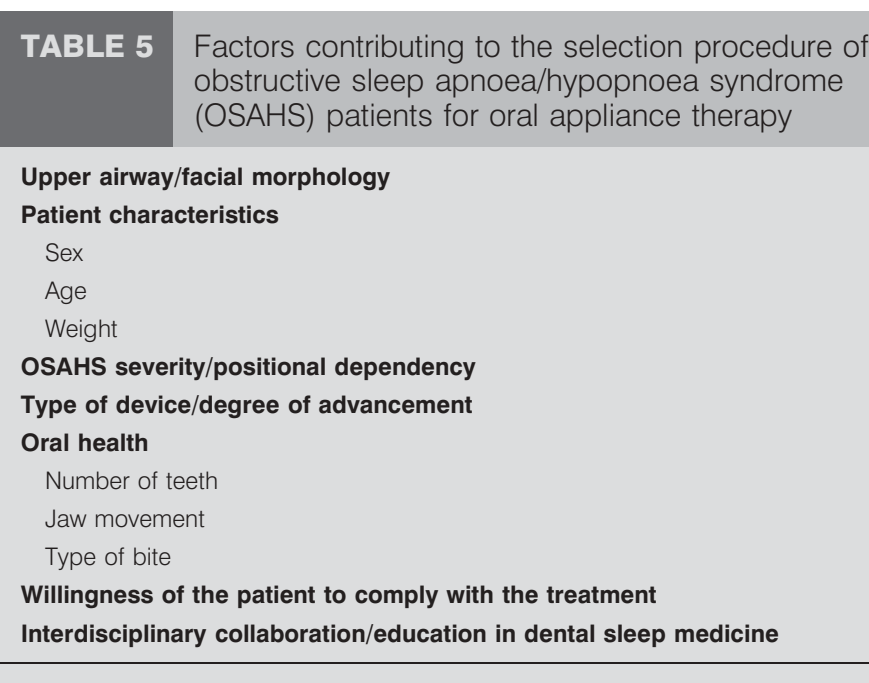

plane angles and smaller mandibles $[96,97]$ who use the same degree of mandibular advancement. These findings are supported by a study that shows a poorer effect from the device in patients with a steep mandibular plane and a long anterior face height [98]. Many of these anatomical predictor variables are, however, difficult to use in clinical practice at present, since no definite cut-off points for treatment success have been suggested. Cephalograms have insufficient prediction possibilities regarding successful treatment with oral appliances; therefore, they are not considered a prerequisite for all patients who are considered for oral appliance therapy [2]. Newer prediction methods that combine different techniques may increase the chances to assess the treatment response with MRAs. DE BACKER et al. [99] have used computational fluid dynamics to calculate effects from MRAs based on advanced three-dimensional and patient-specific images, which represents an interesting future approach to the prediction problem. BATTAGEL et al. [100] have worked with sleep endoscopy to predict treatment effects from MRAs in accordance with what has been performed before UA surgery in patients with sleep apnoea. The predicted result from a mandibular advancement procedure was confirmed, or better, with the device in place in 18 of 27 patients $(67 \%)$ with a predominant velopharyngeal collapse using this technique. In seven out of the 27 patients $(28 \%)$, the effect of the device was worse than the predicted outcome. The overall success rate, defined as an AHI $<10$ events $\cdot h^{-1}$ with the device, was as high as $79 \%$ in 19 re-evaluated patients who were all predicted to improve by the treatment in that study. The patients who did not improve by the device had not advanced their mandibles optimally for treatment success.

Finally, SANNER et al. [101] evaluated the predictive value of the elimination of the pharyngeal collapse during mandibular advancement and a concomitant Mueller manoeuvre visualised by magnetic resonance imaging. Mueller's manoeuvre is designed to look for the site of UA collapse during wakefulness. With a flexible scope positioned in the UA, the patient tries to inspire against a closed mouth and pinched nostrils. The inspiratory forces then serve to collapse the airway. By doing this, an idea can be gained of the relative collapsibility of the palate as compared with the base of tongue or the hypopharynx, the involvement of the lateral walls and the collapse pattern (either circumferential or antero-posterior). SANNER et al. [101] found that all five patients who had patent airways during the Mueller manoeuvre with the device were responders, and six out of eight patients with persistent airway occlusion were nonresponders to the treatment. The site of collapse without the device in place has also created interest and there are indications that an oropharyngeal collapse particularly predicts a favourable response to MRA [100, 102]. A velopharyngeal collapse may be more difficult to treat with an oral appliance, although a favourable response has not been ruled out by initial results in a few patients [100, 102]. Validation of these prediction methods and the testing of their strength in larger samples may result in useful prediction methods in the future.

\section{Patient characteristics: sex, age and weight}

Recent research indicates that there is a sex difference in treatment effect in favour of females [103]. Females with a mild disease have a higher chance of treatment success than females with more severe sleep apnoea [103]. Younger and leaner patients have also been found to benefit more from the appliance compared with older and more obese patients, but the results have been inconsistent between studies [90, 91, 103, 104]. LIU et al. [91] found that, in a sample of 37 subjects with mild-to-severe OSAHS, the poor responders were on average aged $60 \mathrm{yrs}$ and had an average BMI of $32 \mathrm{~kg} \cdot \mathrm{m}^{-2}$, while the good responders were on average aged 44 yrs and had an average BMI of $27 \mathrm{~kg} \cdot \mathrm{m}^{-2}$. RANDERATH et al. [104] showed that responders to MRA treatment were 6 yrs younger than nonresponders. Moreover, a weight increase of $3 \mathrm{~kg}$ or more during treatment has been related to an increased risk of failure with MRAs [92, 103].

The pharynx is longer and the soft palate more voluminous in males than in females [105]. These factors probably contribute to an increased pharyngeal collapsibility and the reduced chance of treatment success with an MRA in males, despite the fact that males have a wider pharynx than females [106, 107]. Males also reduce their UA dimensions more when they move their lower jaws backwards from a rest position [108] and obtain a smaller enlargement from a mandibular advancement procedure compared with females [100].

With age, females increase their pharyngeal length and their soft palate volume more than males do, which probably levels out some of the sex differences in pharyngeal morphology [109]. Ageing also results in a reduced genioglossus activity in response to negative pressure, particularly in males, and increased deposition of fat tissue in the airways in both sexes [109]. These morphological differences may explain why it is more difficult to avoid UA collapse by the simple mandibular repositioning procedure in males than in females, in older individuals compared with in younger ones and with increased weight.

\section{OSAHS severity/positional dependency}

Patients with a milder disease have a higher success rate with the MRA device compared with patients with a more severe disease, $57-81 \%$ versus $14-61 \%$ success rates, respectively [11]. Consequently, it is particularly important to identify more prediction methods for patients with severe sleep apnoea. 
Another approach is to assess the degree of positional dependency in the sleep-disordered breathing events for prediction purposes. The occurrence of supine-dependent sleep apnoeas, defined as a supine AHI of $\geqslant 10$ events $\cdot h^{-1}$ together with a nonsupine AHI of $<10$ events $\cdot h^{-1}$, is a strong predictor for treatment success, particularly among males, with an adjusted odds ratio of 6 [103].

Patients with supine-dependent sleep apnoeas have a more normal pharyngeal morphology than patients with nonsupinedependent sleep apnoeas [110]. An increased apnoea frequency in the nonsupine position indicates a highly collapsible airway $[53,111]$. It is possible that the constricted pharynx in patients with a more severe disease is less treatable with the simple mandibular advancement procedure compared with the more normal configuration of the pharynx in patients with supine-dependent sleep apnoeas. Future research on prediction possibilities with MRAs must also include effects on snoring and other symptoms, not only apnoea reduction.

\section{Advancement procedure and type of device}

The effects of MRAs depend on the degree of mandibular repositioning by the device, in a manner similar to the influence of pressure from the CPAP on sleep apnoeas, snoring and symptoms. A dose-dependent effect from mandibular advancement has been found [103, 112-115], while the degree of mandibular opening within a specific range is probably of less importance for the efficacy of the device [103, 116]. Still, advancements within a wide range, from 0-12 mm [103, 112, 117], and openings of 4-14 $\mathrm{mm}$ have been related to treatment success [52]. The degree of advancement is more important in patients with a more severe disease, since the apnoea reduction is more marked in these patients, together with larger advancements compared with smaller repositionings; this difference was not found in the milder cases [103, 115]. It is possible that specific subgroups of patients are more sensitive to the degree of mandibular repositioning in order to receive treatment success with the device.

There are numerous types of MRAs, but no gold standard device has been identified so far. Custom-made MRAs are most effective. New data show that a prefabricated MRA of the boil-and-bite type is ineffective in reducing sleep apnoeas compared with a custom-made device [118]. This may be explained by poorer fixation to the teeth of prefabricated devices compared with an MRA which is made to fit the individual dentition. The influence of other construction details on the effects of the device is unclear: a two-piece device, which is connected by tubes that allow some movement of the lower jaw, such as the Herbst appliance, might differ in its effects on sleep apnoeas compared with a more rigid connection with a fixed screw. There are several questions regarding the exact design of the device, including a need for more knowledge regarding how long the various types of device will last.

Oral health: number of teeth, jaw movement and type of bite For retention of the MRA in the mouth, a sufficient number of teeth and optimal oral health are necessary in order for the patient to receive enough benefits for the treatment to outweigh the risk of side-effects. As many as 34\% of patients in a sleep apnoea clinic were found to have odontological contraindications [119]. A restricted capacity to move the lower jaw forwards may also reduce the possibilities to receive optimal results with this treatment modality. Finally, the type of bite may interfere with treatment. A normal bite may develop into a mesial occlusion, i.e. the lower teeth become anterior to the upper teeth. Distal occlusion (i.e. the upper teeth are more anterior to the lower teeth than in the normal bite) may be normalised by the device [29]. A deep bite [29], with the upper incisors interlocking the lower ones with $\geqslant 3 \mathrm{~mm}$ provides protection for long-term bite changes [30]. The use of a soft elastomeric appliance, extending over the alveolar processes, or a smaller repositioning by the appliance have also been found to reduce the change in dental occlusion compared with the use of a hard acrylic appliance, fixed only to the teeth, or larger displacements of the lower jaw by the appliance [30]. Unacceptable dental side-effects often result in recommendations of an alternative treatment, although many patients prefer to continue with their MRAs.

In conclusion, bite changes represent an increasing problem with the common use of MRAs during longer periods of time. The bite changes may, however, be reduced by the individualisation of appliance design, patient selection and the more intense follow-up of patients who risk dental side-effects. The development of MRAs that can prevent bite changes or reduce them would be of importance in the future.

\section{Willingness of the patient to comply with treatment}

About three-quarters of the patients continue with treatment for $1 \mathrm{yr}$, and about one-half of the patients continue for $5 \mathrm{yrs}$, although a variable tolerance to MRA treatment has been reported [11, 30 120,121]. To date, the adherence to treatment has been found to be similar with MRAs and CPAP [13, 15]. Patients often prefer MRAs to CPAP, although this probably depends on factors such as the efficacy of the treatment and the design of the appliances [13].

\section{Interdisciplinary collaboration}

Treatment with MRAs requires close collaboration between the sleep apnoea clinic, the dental clinic and dental laboratory. Organisation of routines for patient selection, follow-up of effects and side-effects and the overall health of patients is necessary. Continuous education and the exchange of knowledge between different areas of expertise in this new field of sleep medicine will be of particular importance for this highly interdisciplinary treatment modality.

\section{CONCLUSIONS}

The selection of the best candidates for alternative therapies, from OSAHS patients unwilling to use CPAP or those who have failed with that treatment, is based on patients characteristics, the results from the sleep apnoea recording and a clinical UA examination, which is complemented with other techniques when appropriate. Pre-operative determination of the site(s) of UA obstruction is of paramount importance in the selection of surgical candidates and techniques. Sleep endoscopy can provide important information to determine the site(s) of UA obstruction during sleep and to document specific anatomical features that distinguish OSAHS patients from normal controls. Cephalometry is important not only to determine suitable candidates for the successful cure of 
OSAHS by MMA, but also for the diagnosis of craniofacial abnormalities as a major reason for UA collapsibility in $\sim 40 \%$ of OSAHS patients. In some patients, more information must be achieved by functional tests, such as measurement of critical closing pressure.

The importance of patient-related factors, such as OSAHS severity, obesity and comorbid conditions, varies between the treatment alternatives. The role and relevance of OSAHS severity in UA surgery is not yet clearly understood, although severity does not play any role in the decision for MMA, upper airway soft tissue corrections may be problematic in severe OSAHS. MRAs are less effective in patients with more severe OSAHS, particularly in untreated males with nonsupine sleep apnoeas. MRAs have been found to be more successful in females than males, but no such relationship has been found with the surgical methods. Excessive obesity is a relative contraindication for any kind of surgery. Weight loss should be achieved prior to surgery under accompanying conservative treatment with either CPAP or MRAs, although increased weight also probably reduces the chances of treatment success with mandibular repositioning appliances. Despite the fact that some specific subgroups of patients have smaller chances of treatment success with MRAs, the success rates are high enough to justify a trial with this treatment when other methods have failed. In patients with craniofacial abnormalities, particularly those with vertical excess and backwardrotated mandibles, MMA may be considered. Patients with a poor oral health, such as uncontrolled periodontal disease, are generally unsuitable for MRAs and, for those who do not tolerate CPAP, a surgical treatment might be a solution.

Upper airway collapse during sleep is a complex, multifunctional problem. The experience of the individual surgeon performing "sleep surgery" is of major importance in order to offer the individual patient a fitting surgical concept. Currently, an overall applicable surgical procedure does not exist, and the same holds true for conservative treatment with mandibular repositioning appliances.

\section{REFERENCES}

1 Practice parameters for the treatment of obstructive sleep apnea in adults, the efficacy of surgical modifications of the upper airway. Report of the American Sleep Disorders Association. Sleep 1996; 19: 152-155.

2 Kushida CA, Morgenthaler TI, Littner MR, et al. Practice parameters for the treatment of snoring and obstructive sleep apnea with oral appliances: an update for 2005. Sleep 2006; 29: 240-243.

3 Sher AE, Schechtman KB, Piccirillo JF. The efficacy of surgical modifications of the upper airway in adults with obstructive sleep apnea syndrome. Sleep 1996; 19: 156-177.

4 Kezirian EJ, Weaver EM, Yueh B, et al. Incidence of serious complications after uvulopalatopharyngoplasty. Laryngoscope 2004; 114: 450-453.

5 Powel NB, Guilleminault C, Riley RW. Surgical therapy for obstructive sleep apnea. In: Kryger $\mathrm{MH}$, Roth $\mathrm{T}$, Dement WC, eds. Principles and Practice of Sleep Medicine. Philadelphia, PA, WB Saunders Company, 1994; pp. 706-721.
6 Boudewyns A, De Backer WA, Van de Heyning P. Pattern of upper airway obstruction during sleep before and after uvulopalatopharyngoplasty in patients with obstructive sleep apnea. Sleep Med 2001; 2: 309-315.

7 Sher AE. Upper airway surgery for obstructive sleep apnea. Sleep Med Rev 2002; 6: 195-212.

8 Li KK. Surgical therapy for adult obstructive sleep apnea. Sleep Med Rev 2005; 9: 201-209.

9 Hochban W, Brandenburg U, Peter JH. Surgical treatment of obstructive sleep apnea by maxillomandibular advancement. Sleep 1994; 17: 624-629.

10 Deegan PC, McNicholas WT. Pathophysiology of obstructive sleep apnoea. In: McNicholas WT, ed. Respiratory Disorders During Sleep. Sheffield, UK, European Respiratory Society Journals, 1998; pp. 28-62.

11 Ferguson KA, Cartwright RD, Rogers R, SchmidtNowara W. Oral appliances for snoring and obstructive sleep apnea: a review. Sleep 2006; 29: 244-262.

12 Cistulli PA, Gotsopoulos H, Marklund M, Lowe AA. Treatment of snoring and obstructive sleep apnea with mandibular repositioning appliances. Sleep Med Rev 2004; 8: 443-457.

13 Lim J, Lasserson TJ, Fleetham JA, Wright J. Oral appliances for obstructive sleep apnoea. Cochrane Database Syst Rev 1; 2006: CD004435.

14 Schwab RJ, Kuna ST, Remmers JE. Anatomy and physiology of upper airway obstruction. In: Kryger $\mathrm{MH}$, Roth T, Dement WC, eds. Principles and Practice of Sleep Medicine. Philadelphia, PA, Elsevier Saunders, 2005; pp. 983-1000.

15 Ferguson KA, Lowe AA. Oral appliances for sleepdisordered breathing. In: Kryger $\mathrm{MH}$, Roth $\mathrm{T}$, Dement WC, eds. Principles and Practice of Sleep Medicine. Philadelphia, PA, Elsevier Saunders, 2005; pp. 1098-1108.

16 Ryan CF, Love LL, Peat D, Fleetham JA, Lowe AA. Mandibular advancement oral appliance therapy for obstructive sleep apnoea: effect on awake calibre of the velopharynx. Thorax 1999; 54: 972-977.

17 Kyung SH, Park YC, Pae E-K. Obstructive sleep apnea patients with the oral appliance experience pharyngeal size and shape changes in three dimensions. Angle Orthod 2005; 75: 15-22.

18 Tsuiki S, Lowe AA, Almeida FR, Kawahata N, Fleetham JA. Effects of mandibular advancement on airway curvature and obstructive sleep apnoea severity. Eur Respir J 2004; 23: 263-268.

19 Isono $\mathrm{S}$, Tanaka $\mathrm{A}$, Sho $\mathrm{Y}$, Konno A, Nishino $\mathrm{T}$. Advancement of the mandible improves velopharyngeal airway patency. J Appl Physiol 1995; 79: 2132-2138.

$20 \mathrm{Ng} \mathrm{AT}$, Gotsopoulos H, Qian J, Cistulli PA. Effect of oral appliance therapy on upper airway collapsibility in obstructive sleep apnea. Am J Respir Crit Care Med 2003; 168: 238-241.

21 Barnes M, McEvoy RD, Banks S, et al. Efficacy of positive airway pressure and oral appliances in mild to moderate obstructive sleep apnea. Am J Respir Crit Care Med 2004; 170: 656-664.

22 Naismith SL, Winter VR, Hickie IB, Cistulli PA. Effect of oral appliance therapy on neurobehavioural functioning 
in obstructive sleep apnea: a randomized controlled trial. J Clin Sleep Med 2005; 1: 374-380.

23 Hoffstein V. Snoring and upper airway resistance. In: Kryger MH, Roth T, Dement WC, eds. Principles and Practice of Sleep Medicine. Philadelphia, PA, Elsevier Saunders, 2005; pp. 1001-1012..

24 Marklund M, Sahlin C, Stenlund H, Persson M, Franklin KA. Mandibular advancement device in patients with obstructive sleep apnea: long-term effects on apnea and sleep. Chest 2001; 120: 162-169.

25 Rose EC, Barthlen G, Staats R, Jonas IE. Therapeutic efficacy of an oral appliance in the treatment of obstructive sleep apnea: a 2-year follow-up. Am J Orthod Dentofac Orthoped 2002; 121: 273-279.

26 Walker-Engström M, Tegelbert A, Wilhelmsson B, Ringqvist I. 4-Year follow-up of treatment with dental appliance or uvulopalatopharyngoplasty in patients with obstructive sleep apnea. A randomized study. Chest 2002; 121: 739-746.

27 Fransson AM, Tegelberg A, Leissner L, Wenneberg BIG. Effects of a mandibular protruding device on the sleep of patients with obstructive sleep apnea and snoring problems: a 2-year follow-up. Sleep Breath 2003; 7: 131-142.

28 Almeida FR, Lowe AA, Sung JO, Tsuiki S, Otsuka R. Long-term sequellae of oral appliance therapy in obstructive sleep apnea patients: Part 1. Cephalometric analysis. Am J Orthod Dentofac Orthoped 2006; 129: 195-204.

29 Almeida FR, Lowe AA, Otsuka N, Fastlicht S, Farhood M, Tsuiki S. Long-term sequellae of oral appliance therapy in obstructive sleep apnea patients: Part 2. Study-model analysis. Am J Orthod Dentofac Orthoped 2006; 129: 205-213.

30 Marklund M. Predictors of long-term orthodontic side effects from mandibular advancement devices in patients with snoring and obstructive sleep apnea. Am J Orthod Dentofac Orthoped 2006; 129: 214-212.

31 Rombaux P, Bertrand B, Boudewyns A, et al. Standard ENT clinical evaluation of the sleep-disordered breathing patient: a consensus report. Acta Otorhinolarygol Belg 2002; 56: 127-137.

32 Friedman M, Ibrahim H, Ninos J. Staging of obstructive sleep apnea/hypopnea syndrome: a guide to appropriate treatment. Laryngoscope 2004; 114: 454-459.

33 Friedman M, Vidyasagar R, Bliznikas D, Joseph NJ. Patient selection and efficacy of pillar implant technique for treatment of snoring and obstructive sleep apnea/ hypopnea syndrome. Otolaryngol Head Neck Surg 2006; 134: 187-196.

34 den Herder C, van Tinteren $H$, de Vries N. Sleep endoscopy versus modified mallampati score in sleep apnea and snoring. Laryngoscope 2005; 115: 735-739.

35 Rama AN, Tekwani SH, Kushida CA. Sites of obstruction in obstructive sleep apnea. Chest 2002; 122: 1139-1147.

36 Faber CE, Grymer L. Available techniques for objective assessment of upper airway narrowing in snoring and sleep apnea. Sleep Breath 2003; 7: 77-86.

37 Peter JH, Becker H, Brandenburg U, et al. Investigations and diagnosis of sleep apnoea syndrome. In: Mc Nicholas
WT, ed. Respiratory Disorders During Sleep. Eur Respir Mon 1998; pp. 106-143.

38 Hessel NS, de Vries N. Diagnostic work-up of socially unacceptable snoring. II. Sleep endoscopy. Eur Arch Otorhinolarygol 2002; 259: 158-161.

39 Knape JTA, Everdingen JJE. Guideline for administration of sedatives and analgesics by physicians who are not anesthesiologists. National organisation for quality assurance in hospitals. Neth J Med 1999; 143: 1098-1102.

40 Quinn SJ, Daly N, Ellis PD. Observation of the mechanism of snoring during sleep nasendoscopy. Clin Otolaryngol 1993; 20: 360-363.

41 Hessel NS, de Vries N. Results of uvulopalatopharyngoplasty after diagnostic work-up with polysomnography and sleep endoscopy; a report of 136 snoring patients. Eur Arch Otorhinolarygol 2003; 260: 91-95.

42 den Herder $\mathrm{C}$, van Tinteren $\mathrm{H}$, de Vries $\mathrm{N}$. Hyoidthyropexia: a surgical treatment for sleep apnea syndrome. Laryngoscope 2005; 115: 740-745.

43 Bowden MT, Kezirian EJ, Utley D, Goode RL. Outcomes of hyoid suspension for the treatment of obstructive sleep apnea. Arch Otolaryngol Head Neck Surg 2005; 131: 440-445.

44 Bacon WH, Turlot JC, Krieger J, Stierle JL. Cephalometric evaluation of pharyngeal obstructive factors in patients with sleep apneas syndrome. Angle Orthodontist 1990; 60: 115-121.

45 Hochban W, Brandenburg U. Morphology of the viscerocranium in obstructive sleep apnea syndrome: cephalometric evaluation of 400 patients. J Cranio-Maxillofacial Surg 1994; 22: 205-213.

46 Pépin JL, Ferretti G, Veale D, et al. Somnofluoroscopy, computed tomography, and cephalometry in the assessment of the airway in obstructive sleep apnoea. Thorax 1992; 47: 150-156.

47 Pracharktam N, Hans MG, Strohl KP, Redline S. Upright and supine cephalometric evaluation of obstructive sleep apnea syndrome and snoring subjects. Angle Orthod 1994; 64: 63-74.

48 Riha RL, Brander P, Vennelle M, Douglas NJ. A cephalometric comparison of patients with the sleep apnea/hypopnea syndrome and their siblings. Sleep 2005; 28: 315-320.

49 Millman RP, Carlisle CC, Rosenberg C, Kahn D, McRae R, Kramer NR. Simple predictors of uvulopalatopharygoplasty outcome in the treatment of obstructive sleep apnea. Chest 2000; 118: 1025-1030.

50 Hochban W, Kunkel M, Brandenburg U. Functional anatomy of the upper respiratory tract: cephalometry and acoustic rhinometry. Pneumologie 1993; 47: 766-772.

51 Gold AR, Schwartz AR. The pharyngeal critical pressure. The whys and hows of using nasal continuous positive airway pressure diagnostically. Chest 1996; 110: 10771088.

52 Knaack L, Canisius S, Hochban W, Penzel T, Peter JH. Maxillo-mandibular advancement reduces sleep disordered breathing but does not normalize upper airway mechanics. Am J Respir Crit Care Med 2000; 161: A359.

53 Boudewyns A, Punjabi N, Van de Heyning P, et al. Abbreviated method for assessing upper airway function in obstructive sleep apnea. Chest, 118: 1031-1041. 
54 Patil SP, Punjabi NM, Schneider $\mathrm{H}, \mathrm{O}^{\prime}$ Donnell $\mathrm{CP}$, Smith PL, Schwartz AR. A simplified method for measuring critical pressures during sleep in the clinical setting. Am J Respir Crit Care Med 2004; 170: 86-93.

55 Boudewyns A, Van de Heyning PH, De Backer WA, et al. Effect of body position and sleep stage on upper airway function in obstructive sleep apnea patients. Am J Respir Crit Care Med 1998; 157: A55.

56 Oliven A, O’Hearn D, Boudewyns A, et al. Upper airway response to electrical stimulation of the genioglossus in obstructive sleep apnea. J Appl Physiol 2003; 95: 20232029.

57 Schwartz AR, Schubert NM, Rothman W, et al. Effect of uvulopalatopharyngoplasty on upper airway collapsibility in obstructive sleep apnea. Am Rev Respir Dis 1992; 145: 527-532.

58 Schwartz AR, Gold AR, Schubert NM, et al. Effect of weight loss on upper airway collapsibility in obstructive sleep apnea. Am Rev Respir Dis 1991; 144: 494-498.

59 Janson C, Gislason T, Bengtsson $\mathrm{H}$, et al. Long-term follow-up of patients with obstructive sleep apnea treated with uvulopalatopharyngoplasty. Arch Otolaryngol Head Neck Surg 1997; 123: 257-262.

60 Walker EB, Frith RW, Harding DA, Cant BR. Uvulopalatopharyngoplasty in severe idiopathic obstructive sleep apnoea syndrome. Thorax 1989; 44: 205-208.

61 Friedman M, Vidyasagar R, Bliznikas D, Joseph N. Does severity of obstructive sleep apnea/hypopnea syndrome predict uvulopalatopharyngoplasty outcome? Laryngoscope 2005; 115: 2109-2113.

62 Hessel NS, de Vries N. Increase of the apnoea-hypopnoea index after uvulopalatopharyngoplasty: analysis of failure. Clin Otolaryngol 2004; 29: 682-685.

63 Young T, Skatrud J, Peppard PE. Risk factors for obstructive sleep apnea in adults. JAMA 2004; 291: 2013-2016.

64 Riley RW, Powel NB, Guilleminault C. Obstructive sleep apnea syndrome: a review of 306 consecutively treated surgical patients. Otolaryngol Head Neck Surg 1993; 108: 117-125.

65 Larsson H, Carlsson-Norlander B, Svandborg E. Fouryear follow-up after uvulopalatopharyngoplasty in 50 unselected patients with obstructive sleep apnea syndrome. Laryngoscope 1994; 104: 1362-1368.

66 Passannante AN, Rock P. Anesthetic management of patients with obesity and sleep apnea. Anesthesiol Clin N Am 2005; 23: 479-491.

67 Li KK, Powel NB, Riley RW, Zonato A, Gervacio L, Guilleminault C. Morbidly obese patients with severe obstructive sleep apnea: is airway reconstructive surgery a viable treatment option? Laryngoscope 2000; 110: 982987.

68 Sanders MH. Article reviewed: morbidly obese patients with severe obstructive sleep apnea: is airway reconstructive surgery a viable treatment option. Sleep Med 2001; 2: 77-79.

69 Hochban W, Conradt R, Brandenburg U, Heitmann J, Peter JH. Surgical maxillofacial treatment of obstructive sleep apnea. Plastic Reconstr Surg 1997; 199: 619-626.

70 Hochban W. Surgical treatment of obstructive sleep apnea. Otorhinolaryngol Nova 2000; 10: 149-161.
71 Hochban W. Skeletal facial corrections. In: Johnson JT, Gluckman JL, Sanders MM, eds. Management of Obstructive Sleep Apnea. London, Martin DunitzVerlag, 2002; pp. 193-209.

72 Peker Y, Hedner JA, Norum J, Kraiczi H, Carlson J. Increased incidence of cardiovascular disease in middleaged men with obstructive sleep apnea. A 7-year followup. Am J Respir Crit Care Med 2002; 166: 159-165.

73 Harsch IA, Hahn EG, Konturek PC. Insulin resistance and other metabolic aspects of the obstructive sleep apnea syndrome. Med Sci Monit 2005; 11: 70-75.

74 Meoli AL, Rosen CL, Kristo D, et al. Upper airway management of the adult patient with obstructive sleep apnea in the perioperative period-avoiding complications. Sleep 2003; 26: 1060-1065.

75 Hsueh-Yu L, Pa-Chun W, Chung-Yao H, Shee-Wei L, Ning-Hung C, Shih-An L. Combined nasal-palatopharyngeal surgery for obstructive sleep apnea: simultaneous or staged? Acta Oto-laryngologica 2005; 125: 1-5.

76 Busaba NY. Same-stage nasal and palatopharyngeal surgery for obstructive sleep apnea: is it safe? Otolaryngol Head Neck Surg 2002; 126: 399-403.

77 Li KK, Riley RW, Powel NB, Zonato A, Troell R, Guilleminault C. Postoperative airway findings after maxillomandibular advancement for obstructive sleep apnea syndrome. Laryngoscope 2000; 110: 325-327.

78 Stuck BA, Starzak K, Verse T, Hörmann K, Maurer J. Complications of temperature-controlled radiofrequency volumetric tissue reduction for sleep-disordered breathing. Acta Otolaryngol 2003; 123: 532-535.

79 Stuck BA, Maurer JT, Verse T, Hörmann K. Tongue base reduction with temperature-controlled radiofrequency volumetric tissue reduction for treatment of obstructive sleep apnea syndrome. Acta Otolaryngol 2002; 122: 531536.

80 Li KK, Powel NB, Riley RW, Guilleminault C. Temperature-controlled radiofrequency tongue base reduction in sleep-disordered breathing: long-term outcomes. Otolaryngol Head Neck Surg 2002; 127: 230-234.

81 Fischer Y, Khan M, Mann WJ. Multilevel temperaturecontrolled radiofrequency therapy of soft palate, base of tongue, and tonsils in adults with obstructive sleep apnea. Laryngoscope 2003; 113: 1786-1791.

82 Kao YH, Shnayder Y, Lee KC. The efficacy of anatomically based multilevel surgery for obstructive sleep apnea. Otolaryngol Head Neck Surg 2003; 129: 327-335.

$83 \mathrm{Li}$ KK, Guilleminault C, Riley RW, Powell NB. Obstructive sleep apnea and maxillomandibular advancement: an assessment of airway changes using radiographic and nasopharyngoscopic examinations. J Oral Maxillofac Surg 2002; 60: 526-530.

84 Conradt R, Hochban W, Brandenburg U, Heitmann J, Peter JH. Long term results after surgical treatment of obstructive sleep apnea by maxillomandibular advancement. Eur Respir J 1997; 10: 123-128.

85 Conradt R, Hochban W, Heitmann J, Cassel W. Sleep fragmentation and daytime vigilance in patients with OSA treated by surgical maxillomandibular advancement compared to CPAP-therapy. J Sleep Res 1998; 7: 217-223. 
86 Gupta VK, Reiter ER. Current treatment practices in obstructive sleep apnea and snoring. Am J Otolaryngol 2004; 25: 18-25.

87 Van Lierde KM, Van Borsel J, Moerman M, Van Cauwenberge P. Nasalance, nasality, voice, and articulation after uvulopalatopharyngoplasty. Laryngoscope 2002; 112: 873-878.

88 Yoshida K. Prostethic therapy for sleep apnea syndrome. J Prosthet Dent 1994; 72: 452-460.

89 Mayer G, Meier-Ewert K. Cephalometric predictors for orthopaedic mandibular advancement in obstructive sleep apnoea. Eur J Orthod 1995; 17: 35-43.

90 Liu Y, Park Y-C, Lowe AA, Fleetham JA. Supine cephalometric analysis of an adjustable oral appliance used in the treatment of obstructive sleep apnea. Sleep Breath 2000; 4: 59-66.

91 Liu Y, Lowe AA, Fleetham JA, et al. Cephalometric and physiologic predictors of the efficacy of an adjustable oral appliance for treating obstructive sleep apnea. Am J Orthod Dentofac Orthoped 2001; 120: 639-647.

92 Otsuka R, de Almeida FR, Lowe AA, Ryan F. A comparison of responders and nonresponders to oral appliance therapy for the treatment of obstructive sleep apnea. Am J Orthod Dentofac 2006; 129: 222-229.

93 Mehta A, Qian J, Petocz P, et al. A randomized, controlled study of a mandibular advancement splint for obstructive sleep apnea. Am J Respir Crit Care Med 2001; 163: 14571461.

94 Suratt PM, McTier RF, Wilhoit SC. Upper airway muscle activation is augmented in patients with obstructive sleep-apnea/hypopnea syndrome. Am J Respir Crit Care Med 1995; 152: 721-724.

95 Fogel RB, Trinder J, White D, et al. The effect of sleep onset on upper airway muscle activity in patients with sleep apnoea versus controls. J Physiol 2005; 564: 549-562.

96 Gao X, Otsuka R, Ono T, Honda E, Sasaki T, Kuroda T. Effect of titrated mandibular advancement and jaw opening on the upper airway in nonapneic men: a magnetic resonance imaging and cephalometric study. Am J Orthod Dentofac Orthoped 2004; 125: 191-199.

97 L' Estrange PR, Battagel JM, Harkness B, et al. A method of studying adaptive changes of the oropharynx to variation in mandibular position in patients with obstructive sleep apnoea. J Oral Rehabil 1996; 23: 699-711.

98 Marklund M, Franklin KA, Stenlund H, Persson M. Mandibular morphology and the efficacy of a mandibular advancement device in patients with sleep apnoea. Eur J Oral Sci 1998; 106: 914-921.

99 De Backer J, Gorlé C, Vanderveken O, et al. Predicting the effect of a mandibular advancement device (MAD) in sleep apnea (SA) or symptomatic snoring (SS) patients by computational fluid dynamics (CFD). Eur Respir J 2005; 26: Suppl. 49, S200.

100 Battagel JM, Johal A, Kotecha BT. Sleep nasendoscopy as a predictor of treatment success in snorers using mandibular advancement splints. J Laryngol Otol 2005; 119: 106-112.

101 Sanner BM, Heise M, Knoben B, et al. MRI of the pharynx and treatment efficacy of a mandibular advancement device in obstructive sleep apnoea syndrome. Eur Respir J 2002; 20: 143-150.
102 Henke KG, Frantz DE, Kuna ST. An oral elastic mandibular advancement device for obstructive sleep apnea. Am J Respir Crit Care Med 2000; 161: 420-425.

103 Marklund M, Stenlund H, Franklin KA. Mandibular advancement devices in 630 men and women with obstructive sleep apnea and snoring. Tolerability and predictors of treatment success. Chest 2004; 125: 12701278.

104 Randerath W, Heise M, Hinz R, Ruehle KH. An individually adjustable oral appliance vs continuous positive airway pressure in mild-to-moderate obstructive sleep apnea syndrome. Chest 2002; 122: 569-575.

105 Malhotra A, Huang Y, Fogel RB, et al. The male predisposition to pharyngeal collapse: the importance of airway length. Am J Respir Crit Care Med 2002; 166: 1388-1395.

106 Mohsenin V. Gender differences in the expression of sleep-disordered breathing: role of upper airway dimensions. Sleep Med Rev 2003; 120: 1442-1447.

107 Kapsimalis F, Kryger MH. Gender and obstructive sleep apnea syndrome. Part 1: clinical features. Sleep 2002; 25: 412-419.

108 Mohsenin V. Effects of gender on upper airway collapsibility and severity of obstructive sleep apnea. Sleep Med 2003; 4: 523-529.

109 Malhotra A, Huang Y, Fogerl R, et al. Aging influences on pharyngeal anatomy and physiology: the predisposition to pharyngeal collapse. Am J Med 2006;119: 72 e9-e14.

110 Pevernagie DA, Stanson AW, Sheedy PF. Effects of body position on the upper airway of patients with obstructive sleep apnea. Am J Respir Crit Care Med 1995; 152: 179-185.

111 Isono S, Tanaka A, Nishino S. Lateral position decreases collapsibility of the passive pharynx in patients with obstructive sleep apnea. Anesthesiology 2002; 97: 780-785.

112 Almeida FR, Bittencourt LR, de Almeida CI, Tsuiki S, Lowe AA, Tufik S. Effects of mandibular posture on obstructive sleep apnea severity and the temporomandibular joint in patients fitted with an oral appliance. Sleep 2002; 25: 507-513.

113 Kato J, Isono S, Tanaka A, et al. Dose-dependent effects of mandibular advancement on pharyngeal mechanics and nocturnal oxygenation in patients with sleep-disordered breathing. Chest 2000; 117: 1065-1072.

114 Pételle B, Vincent G, Gagnadoux F, Rakotonanahary D, Meyer B, Fleury B. One-night mandibular advancement titration for obstructive sleep apnea syndrome: a pilot study. Am J Respir Crit Care Med 2002; 165: 1150-1153.

115 Walker-Engström M, Ringqvist I, Vestling O, Wilhelmsson B, Tegelberg A. A prospective randomized study comparing two different degrees of mandibular advancement with a dental appliance in the treatment of severe obstructive sleep apnea. Sleep Breath 2002; 7: 119-130.

116 Pitsis AJ, Darendeliler MA, Gotsopoulos H, Petocz P, Cistulli PA. Effect of vertical dimension on efficacy of oral appliance therapy in obstructive sleep apnea. Am J Respir Crit Care Med 2002; 166: 860-864.

117 Tegelberg A, Walker-Engström M, Vestling O, Wilhelmsson B. Two different degrees of mandibular advancement with a dental appliance in treatment of patients with mild to moderate obstructive sleep apnea. Acta Odontol Scand 2003; 61: 356-362. 
118 Vanderveken O, Marklund M, Braem MJ, et al. Comparison of a custom-made and a prefabricated mandibular advancement device for treatment of sleepdisordered breathing: a prospective, randomized crossover trial. Proc Am Thorac Soc 2006; 2: A612.

119 Petit FX, Pépin JL, Bettega G, Sadek H, Raphaël B, Lévy P. Mandibular advancement devices. Rate of contraindications in 100 consecutive obstructive sleep apnea patients. Am J Respir Crit Care Med 2002; 166: 274-278.
120 Izci B, McDonald JP, Coleman EL, Mackay TW Douglas NJ, Engleman HM. Clinical audit of subjects with snoring and sleep apnoea/hypopnoea syndrome fitted with mandibular repositioning splint. Respir Med 2005; 99: 337-346.

121 McGown AD, Makker HK, Battagel JM, L'Estrange PR, Grant HR, Spiro SG. Long-term use of mandibular advancement splints for snoring and obstructive sleep apnoea: a questionnaire survey. Eur Respir J 2001; 7: 462-466. 